\title{
Vegetative Compatibility Groups and Pathogenicity Among Isolates of Fusarium oxysporum f. sp. cucumerinum
}

\author{
Il-Pyung Ahn, Hoo-Sup Chung, and Yong-Hwan Lee, Department of Agricultural Biology and Research Center \\ for New Bio-Materials in Agriculture, College of Agriculture and Life Sciences, Seoul National University, Suwon \\ 441-744, Korea
}

\begin{abstract}
Ahn, I. P., Chung, H. S., and Lee, Y.-H. 1998. Vegetative compatibility groups and pathogenicity among isolates of Fusarium oxysporum f. sp. cucumerinum. Plant Dis. 82:244-246.

Seventy-eight isolates of Fusarium oxysporum f. sp. cucumerinum, the causal agent of cucumber wilt, were isolated from symptomatic tissues of cucumber from four provinces in Korea. These isolates were grouped into vegetative compatibility groups (VCGs) by demonstrating heterokaryosis by complementation tests using nitrate nonutilizing (nit) mutants. All isolates were grouped into six VCGs-1-A, 1-B, 1-C, 1-D, 1-E, and 1-F. No self-incompatibility was observed in any of the isolates tested. VCG 1-A was the most common group within growing regions in Korea and proved to be the most virulent of the VCGs identified. These data indicate that the level of virulence in $F$. oxysporum $\mathrm{f}$. sp. cucumerinum is related to VCG.
\end{abstract}

Additional keywords: Cucumis sativus, genetic diversity, nit mutant

Fusarium wilt of cucumber (Cucumis sativus L.), caused by Fusarium oxysporum (Schlechtend.:Fr.) f. sp. сисиmerinum (Owen) Snyder \& Hansen, is manifested in young and mature plants throughout cucumber-growing regions $(2,10,16)$. This disease is one of the major limiting factors for stable production of cucumber, since highly resistant cultivars have not been developed and effective control methods are not available. Accurate analysis of the population structure of the causal fungus would be helpful in developing effective control methods for this disease.

In 1985, Puhalla (18) found a correlation between vegetative compatibility group (VCG) and formae speciales of $F$. oxysporum, i.e., members of a VCG belong to the same forma specialis. He suggested that when the sexual stage and meiotic recombination in $F$. oxysporum were lost, the loci that determine vegetative incompatibility (vic or het loci) and virulence became closely linked. Therefore, VCG analysis of populations of $F$. oxysporum has been used as a powerful tool to classify between nonpathogenic and pathogenic populations on the same host species $(1,7,11)$, classify races $(3,14)$, and assess genetic homogeneity among populations $(6,8,17)$. Furthermore, VCG has been used

Corresponding author: Y.-H. Lee

E-mail: yonglee@plaza.snu.ac.kr

Accepted for publication 1 November 1997.

Publication no. D-1997-1208-03R

(C) 1998 The American Phytopathological Society to estimate the virulence level of the isolates in $F$. moniliforme (13). Although extensive studies on VCG with races, formae speciales, and virulence of $F$. oxysporum have been conducted, no reports are available on $F$. oxysporum f. sp. cucumerinum.

The objectives of this study were to investigate genetic diversity within the population of $F$. oxysporum f. sp. сисиmerinum with respect to the vegetative compatibility and to determine the relationship between VCGs and virulence.

\section{MATERIALS AND METHODS}

Fungal strains and virulence tests. Isolates of $F$. oxysporum f. sp. cucumerinum were recovered from diseased cucumber tissues showing typical symptoms (wilting and/or brown discoloration of the vascular system) from four provinces (Kyunggi, Chungnam, Chonnam, and Kyungbuk) in Korea. Diseased tissues were collected from young and mature plants during growing seasons in 1991 and 1992. Identification was performed on the basis of mycological characteristics described by Nelson et al. (15). Virulence tests of all isolates were performed on the susceptible cucumber cv. Sunmi VCu-Hy185 using the method described by Jacobson and Gordon (8). Disease severity ratings were recorded at 4 weeks after inoculation using a $0-4$ scale, where 0 represents no disease; 1 = slight chlorosis and wilting; $2=$ wilting and slight discoloration of vascular system; 3 = severe wilting and brown discoloration of vascular system; and $4=$ complete wilting and plant death. Virulence tests were conducted at least twice for each isolate with 10 replications. $\mathrm{Cu}$ - cumber plants inoculated with potato dextrose broth and isolate CF 8601 were included in each virulence test as a negative and positive control, respectively.

Vegetative compatibility. Nitrate nonutilizing (nit) mutants were generated and the phenotypes of all nit mutants were determined by the methods of Correll et al. (4). These nit mutants of $F$. oxysporum $\mathrm{f}$. sp. cucumerinum produced very thin, expansive growth on minimal medium, which contained nitrate as the sole nitrogen source. Several nit1 and NitM mutants from all isolates were stored in sterile distilled water at $4^{\circ} \mathrm{C}$. Before complementation tests among isolates, vegetative selfincompatibility of each isolate was examined by the method of Jacobson and Gordon (8). nitl and NitM mutants of all 78 isolates of $F$. oxysporum f. sp. cucumerinum were then paired in all possible combinations on minimal medium and the plates were incubated at $26^{\circ} \mathrm{C}$ in dark. Vegetatively compatible isolates were recognized by the robust growth at the interface of the two colonies after 10 days (Fig. 1).

\section{RESULTS}

Sectoring frequency on chloratecontaining medium and phenotype ratio of nit mutants varied among isolates. Five to 24 nit mutants were obtained from each isolate of $F$. oxysporum f. sp. cucumerinum. A total of 2,248 nit mutants were obtained from the 78 isolates. The nit 1 phenotype was recovered most frequently $(51.3 \%)$, followed by $\mathrm{NitM}(24.2 \%)$ and nit3 (5.2\%). The rest of the mutants were not classified as one of the three phenotypes. Several nit1 and NitM mutants from each isolate were selected for complementation tests. No self-incompatibility was observed between complementary nit mutants recovered from the same isolate of $F$. oxysporum f. sp. cucumerinum. Based on pairing complementary nit mutants of all isolates, mainly with nitl and NitM mutants, the 78 isolates were grouped into six VCGs. They consisted of one large VCG (41 isolates), arbitrarily designated as 1-A, and five other VCGs-1-B (7 isolates), 1C (8 isolates), 1-D (12 isolates), 1-E (7 isolates), and 1-F (3 isolates). VCG 1-A was widely distributed throughout the collection area (Table 1).

All 78 isolates caused disease symptoms on cucumber cv. Sunmi VCu-Hy-185, but the level of virulence of each isolate varied 
greatly. Mean virulence of isolates in VCG 1-A was higher than those of other VCGs. Thirty-three out of 41 isolates $(80 \%)$ in VCG 1-A were rated as more than a disease severity score 3 . There were no significant differences in mean virulence for isolates in VCGs 1-B, 1-C, 1-D, 1-E, and 1-F (Table 1). No relationship was observed between the origin of isolates and virulence.

\section{DISCUSSION}

Seventy-eight isolates of $F$. oxysporum f. sp. cucumerinum collected from four provinces in Korea were grouped into 6 VCGs. VCG 1-A, the largest VCG, was distributed throughout all sites and con- sisted of 41 isolates (53\%). The recovery of isolates in VCG 1-A from diverse locations indicates that this genetically homogeneous population is widespread among geographically separated regions. This phenomenon has been frequently observed in other formae speciales of $F$. oxysporum $(6,11,12,17)$. The occurrence of a VCG in more than one region could be explained by an initial broad distribution of a compatibility group or more recent spread of a VCG from a single geographic origin through seeds, seedlings, diseased debris, and human activities.

A high level of VCG diversity was observed in nonpathogenic populations of $F$.

Table 1. Vegetative compatibility groups and virulence of Fusarium oxysporum f. sp. cucumerinum

\begin{tabular}{|c|c|c|c|c|c|c|}
\hline \multirow[b]{2}{*}{ VCG } & \multicolumn{5}{|c|}{ No. of isolates tested from different provinces } & \multirow[b]{2}{*}{ Virulence $^{\mathrm{z}}$} \\
\hline & Kyunggi & Chungnam & Chonnam & Kyungbuk & Total & \\
\hline $1-\mathrm{A}$ & 35 & 1 & 2 & 3 & 41 & $3.43 \mathrm{a}(2.55-3.94)$ \\
\hline $1-B$ & 5 & - & - & 2 & 7 & $2.52 b(2.57-3.27)$ \\
\hline $1-\mathrm{C}$ & 8 & - & - & - & 8 & $2.51 \mathrm{~b}(1.63-3.04)$ \\
\hline 1-D & 11 & 1 & - & - & 12 & $2.50 \mathrm{~b}(1.52-3.11)$ \\
\hline $1-\mathrm{E}$ & 7 & - & - & - & 7 & $2.64 \mathrm{~b}(1.61-3.12)$ \\
\hline $1-\mathrm{F}$ & 3 & - & - & - & 3 & $2.75 \mathrm{~b}(2.45-2.93)$ \\
\hline Total & 69 & 2 & 2 & 5 & 78 & $3.01(1.52-3.94)$ \\
\hline
\end{tabular}

z Virulence was the mean disease severity value. Disease severity was assessed with a 0-4 scale, where 0 represents no disease; 1 = slight chlorosis and wilting; 2 = wilting and slight discoloration of vascular system; 3 = severe wilting and brown discoloration of vascular system; and $4=$ complete wilting and plant death. Means followed by the same letter are not significantly different, according to Duncan's multiple range tests $(P=0.012)$. The numbers in parentheses indicate the ranges of virulence of isolates in each VCG.

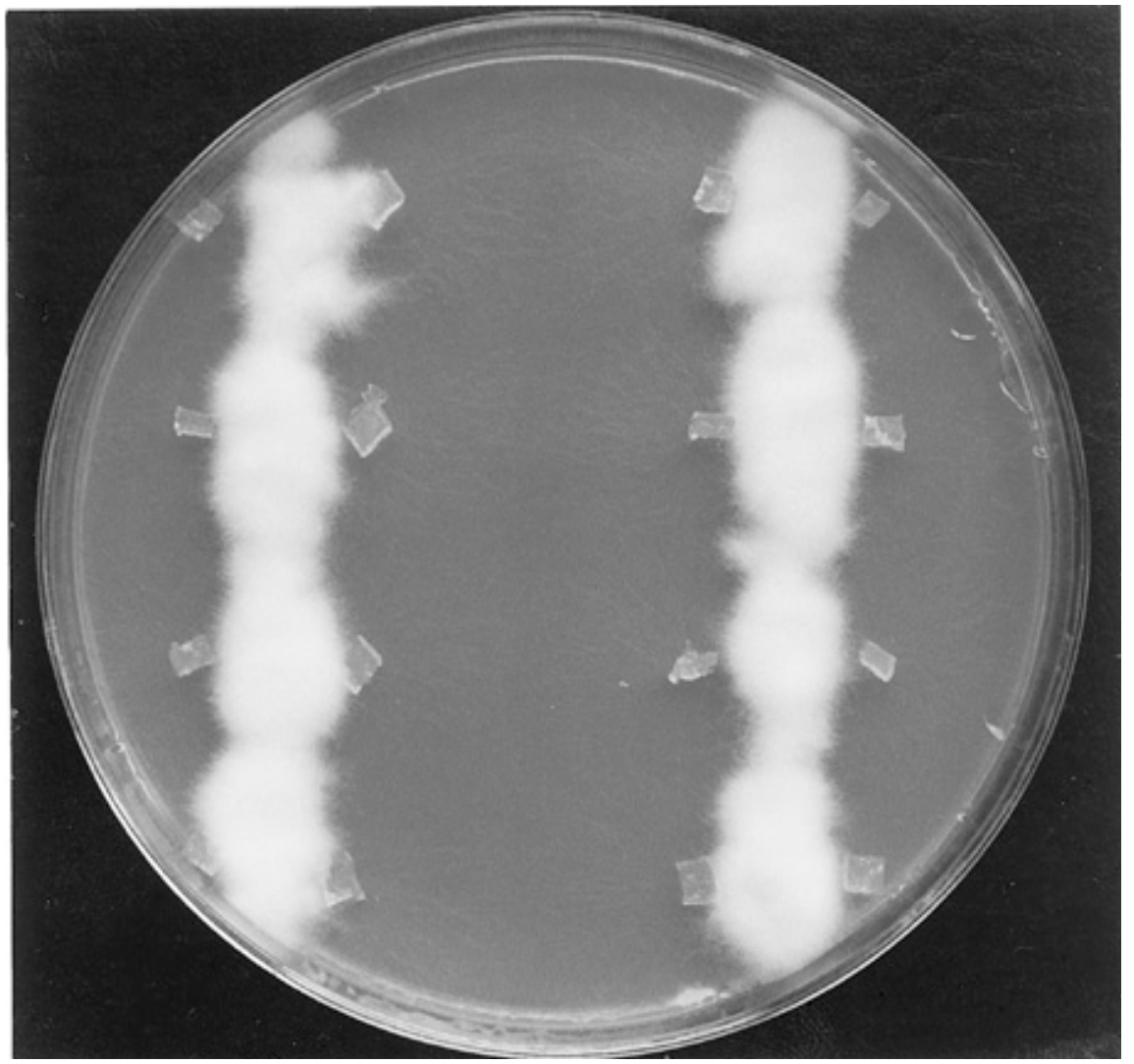

Fig. 1. Complementation tests on the Fusarium minimal medium containing $\mathrm{NaNO}_{3}$ as the sole nitrogen source. Outer mutants (nit1) were generated from different isolates and paired with NitM from isolate CF 8601 (belong to VCG 1-A). Robust mycelial growth indicates complementation between isolates. oxysporum, but one or a few VCG were recovered from pathogenic populations $(1,7,11)$. All 47 isolates of $F$. oxysporum $\mathrm{f}$. sp. apii collected from celery showing wilt symptoms belonged to a single VCG (5). $F$. oxysporum f. sp. melonis collected within a single agricultural field in California also were represented by a single VCG (9). However, 6 VCGs were recovered in Kyunggi province in this study, although VCG 1-A was predominant. This indicates that the population of $F$. oxysporum f. sp. cucumerinum pathogenic to cucumber used in this study is genetically more diverse than other pathogenic populations of $F$. oxysporum. It is not clear whether they evolved from the same clone or independently. Other molecular studies of population diversity would provide insight into the relationship among isolates in different VCGs.

Mean virulence of isolates in VCG 1-A was significantly higher than those of other VCGs. Thirty-three out of 41 isolates in VCG 1-A were rated as more than a disease severity score of 3 , indicating that $80 \%$ of isolates in VCG 1 -A were highly virulent. Isolates in other VCGs had much lower disease severity scores, although a few isolates showed strong virulence. These results suggest that VCG is associated with virulence in $F$. oxysporum $\mathrm{f}$. sp. cucumerinum. A similar relationship has been reported in $F$. moniliforme (13). Furthermore, strong virulence of isolates in VCG 1-A may explain why VCG 1-A was predominant in our collection from cucumber showing disease symptoms in the field.

Host-pathogen interactions between cucumber cultivars and isolates of $F$. oxysporum f. sp. cucumerinum have not been well established. Although virulence is associated with VCGs in this fungal population, the cause of this relationship is not known. It may be useful to monitor the occurrence of VCG 1-A in new production areas for the successful control of cucumber wilt. It would be also very valuable to screen breeding lines of cucumber by genetically diverse groups (VCGs) of the pathogen. To our knowledge, this is the first report of the classification of $F$. oxysporum f. sp. cucumerinum into VCGs.

\section{ACKNOWLEDGMENTS}

This study was supported by the grants from Research Center for New Bio-Materials in Agriculture at Seoul National University and Seoul National University Development Foundation.

\section{LITERATURE CITED}

1. Appel, D. J., and Gordon, T. R. 1994. Local and regional variation in population of Fusarium oxysporum from agricultural field soils. Phytopathology 84:786-791.

2. Armstrong, G. M., and Armstrong, G. K. 1978. Formae speciales and races of Fusarium oxysporum causing wilts of the $\mathrm{Cu}-$ curbitaceae. Phytopathology 68:19-28.

3. Bosland, P. W., and Williams, P. H. 1987. An evaluation of Fusarium oxysporum from crucifers based on pathogenicity, isozyme poly- 
morphism, vegetative compatibility, and geographic origin. Can. J. Bot. 65:2067-2073.

4. Correll, J. C., Klittich, C. J. R., and Leslie, J. F. 1987. Nitrate nonutilizing mutants of Fusarium oxysporum and their use in vegetative compatibility tests. Phytopathology 77:1640-1646

5. Correll, J. C., Puhalla, J. E.,. and Schneider, R. W. 1986. Identification of Fusarium oxysporum f. sp. apii on the basis of colony size, virulence, and vegetative compatibility. Phytopathology 76:396-400.

6. Elias, K. S., and Schneider, R. W. 1991. Vegetative compatibility groups in Fusarium oxysporum f. sp. lycopersici. Phytopathology 81:159-162.

7. Gordon, T. R., and Okamoto, D. 1992. Population structure and the relationship between pathogenic and nonpathogenic strains of Fusarium oxysporum. Phytopathology 82:7377.

8. Jacobson, D. J., and Gordon, T. R. 1988. Vegetative compatibility and self- incompatibility within Fusarium oxysporum $\mathrm{f}$. sp. melonis. Phytopathology 78:668-672.

9. Jacobson, D. J., and Gordon, T. R. 1990 Further investigations of vegetative compatibility within Fusarium oxysporum f. sp. melonis. Can. J. Bot. 68:1245-1248.

10. Jenkins, S. F., Jr., and Wehner, T. C. 1983. Occurrence of Fusarium oxysporum f. sp. cucumerinum on greenhouse-grown Cucumis sativus seed stocks in North Carolina. Plant Dis. 67:1024-1025.

11. Katan, T., and Katan, J. 1988. Vegetative compatibility grouping of Fusarium oxysporum f. sp. vasinfectum from tissues and the rhizosphere of cotton plants. Phytopathology 78:852-855.

12. Katan, T., Zamir, D., Sarfatii, M., and Katan, J. 1991. Vegetative compatibility groups and subgroups in Fusarium oxysporum f. sp. radicis-lycopersici. Phytopathology 81:255262.

13. LaMondia, J. A., and Elmer, W. H. 1989. Pathogenicity and vegetative compatibility among isolates of Fusarium oxysporum and F. moniliforme colonizing asparagus tissues. Can. J. Bot. 67:2420-2424.

14. Larkin, R. P., Hopkins, D. L., and Martin, F. N. 1990. Vegetative compatibility within Fusarium oxysporum f. sp. niveum and its relationship to virulence, aggressiveness, and race. Can. J. Microbiol. 36:352-358

15. Nelson, P. E., Toussoun, T. A., and Marasas, W. F. O. 1983. Fusarium species: An illus trated manual for identification. The Pennsylvania State University Press, University Park. pp. 142-145.

16. Owen, J. H. 1956. Cucumber wilt, caused by Fusarium oxysporum f. cucumerinum n. f. Phytopathology 46:153-157.

17. Ploetz, R. C., and Correll, J. C. 1988. Vegetative compatibility among races of Fusarium oxysporum f. sp. cubense. Plant Dis. 72:325 328.

18. Puhalla, J. E. 1985. Classification of strains of Fusarium oxysporum on the basis of vegetative compatibility. Can. J. Bot. 62:540-545. 